\title{
APLIKASI PRINSIP MAKSIMUM PONTRYAGIN DAN METODE RUNGE-KUTTA DALAM MASALAH KONTROL OPTIMAL
}

\author{
TAUFIK HIDAYAT, JENIZON, BUDI RUDIANTO \\ Jurusan Matematika, \\ Fakultas Matematika dan Ilmu Pengetahuan Alam, Universitas Andalas, \\ Kampus UNAND Limau Manis Padang, Indonesia. \\ email : sekal1.c.th@gmail.com
}

\begin{abstract}
Abstrak. Tulisan ini membahas tentang penggunaan prinsip maksimum pontryagin dan metode Runge-Kutta dalam masalah kontrol optimal. Prinsip maksimum pontryagin digunakan untuk menentukan solusi analitik, dan metode Runge-Kutta untuk menentukan solusi numerik. Hasil dari metode Runge-Kutta kemudian dibandingkan dengan solusi analitiknya. Dari hasil perbandingan dapat disimpulkan metode Runge-Kutta memberikan galat yang sangatlah kecil dan dapat diabaikan.
\end{abstract}

Kata Kunci: Masalah Kontrol Optimal, Prinsip Maksimum Pontryagin, Runge-Kutta

\section{Pendahuluan}

Masalah kontrol optimal merupakan masalah penentuan suatu pengontrol yang memenuhi suatu sistem persamaaan differential/difference dan sekaligus mengoptimumkan suatu kriteria performance (fungsi biaya/fungsi tujuan). Masalah kontrol optimal dapat diselesaikan dengan menggunakan prinsip maksimum Pontryagin. Sejumlah masalah kotrol optimal bersifat non-linier yang tidak mempunyai solusi analitik, oleh karena itu diperlukan sebuah metode numerik untuk menghampiri solusi dari masalah kontrol optimal tersebut.

Tulisan ini membahas penggunaan prinsip maksimum Pontryagin dan metode Runge-Kutta dalam masalah kontrol optimal berikut.

(a) Jarak terpendek antara dua titik. Bentuk tipe masalah ini adalah

$$
\begin{aligned}
\min & \int_{t_{0}}^{T}\left(1+u^{2}\right)^{\frac{1}{2}} d t \\
\text { kendala } & \dot{x}=u, \\
\text { dan } & x\left(t_{0}\right)=x_{0}, x(T) \text { bebas. }
\end{aligned}
$$

(b) Masalah produksi coklat. Masalah khusus di sini adalah dalam bentuk:

$$
\begin{aligned}
\max & \int_{t_{0}}^{2}\left(u^{2}+2 x u-x^{2}\right) d t \\
\text { kendala } & \dot{x}=-u, \\
\text { dan } & x(0)=1, u(0)=0 .
\end{aligned}
$$


(c) Masalah pendulum. Tipe masalah ini membutuhkan deskripsi sistem mekanik pada titik masa $m$ yang dibatasi oleh panjang kabel $l$. Bentuk masalahnya adalah

$$
\begin{aligned}
\min S= & \int_{t_{1}}^{t_{2}}\left(\frac{1}{2} m l^{2} u^{2}-m g l(1-\cos \theta)\right) d t, \\
\text { kendala } & \dot{\theta}=u, \\
\text { dan } & \theta\left(t_{1}\right)=\theta_{0}, \theta(T) \text { bebas. }
\end{aligned}
$$

\section{Tinjauan Teori}

\subsection{Deret Taylor}

Teorema 2.1. [1] (Teorema Taylor) Misalkan $n \in \mathbb{N}, I=[a, b]$, dan $f: I \rightarrow \mathbb{R}$ sedemikian sehingga $f^{\prime}, f^{\prime \prime}, \cdots, f^{(n)}$ kontinu di $I$ dan $f^{(n+1)}$ ada pada $(a, b)$. Jika $x_{0} \in I$, maka untuk setiap $x$ di $I$ terdapat suatu titik $c$ di antara $x$ dan $x_{0}$ sedemikian sehingga

$$
\begin{aligned}
f(x)= & f\left(x_{0}\right)+f^{\prime}\left(x_{0}\right)\left(x-x_{0}\right)+\frac{f^{\prime \prime}\left(x_{0}\right)}{2 !}\left(x-x_{0}\right)^{2}+\cdots \\
& +\frac{f^{(n)}\left(x_{0}\right)}{n !}\left(x-x_{0}\right)^{n}+R_{n}(x),
\end{aligned}
$$

dimana

$$
R_{n}(x)=\frac{f^{(n+1)}(c)}{(n+1) !}\left(x-x_{0}\right)^{n+1}
$$

dan

$$
\lim _{x \rightarrow a} \frac{R_{n}}{(x-a)^{n}}=0 .
$$

\subsection{Persamaan Euler Lagrange}

$$
\frac{\partial F}{\partial y}-\frac{d}{d t}\left(\frac{\partial F}{\partial y^{\prime}}\right)=0 .
$$

Jika $F=F\left(t, u, u^{\prime}\right)$, maka (2.4) menjadi

$$
\frac{\partial F}{\partial u}-\frac{d}{d t}\left(\frac{\partial F}{\partial u^{\prime}}\right)=0
$$

persamaan (2.4) dan (2.5) disebut sebagai persamaan Euler-Lagrange [2].

\subsection{Kalkulus Variasi}

Teorema 2.2. [10] (Teorema Kalkulus Variasi) Asumsikan bahwa F adalah $C^{2}$-fungsi yang terdefinisi di $\mathbb{R}^{3}$. Berdasarkan

$$
\int_{t_{0}}^{t_{1}} f(t, x, \dot{x}) d t
$$


jika suatu fungsi $x^{*}$ maksimum atau minimum pada integral di (2.6) diantara semua $x \in C^{2}\left[t_{0}, t_{1}\right]$ yang memenuhi kondisi titik akhir

$$
x\left(t_{0}\right)=x_{0}, x\left(t_{1}\right)=x_{1}
$$

maka $x^{*}$ memenuhi persamaan Euler-Lagrange

$$
\frac{\partial F}{\partial x}(t, x(t), \dot{x}(t))-\frac{d}{d t}\left(\frac{\partial F}{\partial x}(t, x(t), \dot{x}(t))=0, t \in\left[t_{0}, t_{1}\right] .\right.
$$

Jika fungsi $(x, \dot{x})$ adalah concave (convex) untuk setiap $t \in\left[t_{0}, t_{1}\right]$, maka fungsi $x^{*}$ yang memenuhi (2.7) adalah solusi dari masalah maksimum (minimum).

\subsection{Prinsip Maksimum Pontryagin}

Dalam [2] diberikan Prinsip Maksimum Pontryagin sebagai berikut. Misal diberikan masalah kontrol optimal

$$
\begin{aligned}
\max J(u) & =S(x(T), T)+\int_{0}^{T} F(x, u, t) d t \\
\text { kendala } \dot{x}(t) & =f(x, u, t), x(0)=x_{0} .
\end{aligned}
$$

Syarat perlu agar suatu $u^{*}$ menjadi kontrol optimal pada persamaan di atas adalah

$$
\begin{aligned}
H\left(t, x^{*}, u^{*}, \lambda\right) \geq H(t, x, u, \lambda) & \text { untuk setiap } t \in[0, T], \\
\frac{\partial H}{\partial u}=0, & \text { (Kondisi optimal), } \\
\dot{x}=\frac{\partial H}{\partial \lambda} & \text { (Persamaan state) }, \\
\dot{\lambda}=-\frac{\partial H}{\partial x} & \text { (Persamaan adjoin) }, \\
\lambda(T) \text { bebas } & \text { (Kondisi transversal). }
\end{aligned}
$$

\subsection{Metode Runge-Kutta}

Algoritma untuk metode Runge-Kutta orde empat untuk $\dot{X}=F(t, x, u)$ diberikan oleh [5].

$$
\begin{aligned}
k_{1} & =f\left(t_{i}, x_{i}, u_{i}\right) \\
k_{2} & =f\left(t_{i}+\frac{h}{2}, x_{i}+\frac{h}{2} k_{1}, u_{i}+\frac{h}{2}\right) \\
k_{3} & \left.=f\left(t_{i}+\frac{h}{2}, x_{i}+\frac{h}{2} k_{2}, u_{i}+\frac{h}{2}\right)\right) \\
k_{4} & =f\left(t_{i}+h, x_{i}+h, u_{i}+h\right) \\
u_{i+1} & =u_{i}+\frac{h}{6}\left(k_{1}+2 k_{2}+2 k_{3}+k_{4}\right), i=0,1,2,3, \cdots, N \\
x_{i+1} & =x_{i}+\frac{h}{6}\left(k_{1}+2 k_{2}+2 k_{3}+k_{4}\right), i=0,1,2,3, \cdots, N .
\end{aligned}
$$


Algoritma untuk metode Runge-Kutta orde empat untuk $\dot{\lambda}=F(t, \lambda, x, u)$ diberikan oleh [5] :

$$
\begin{aligned}
k_{1} & =f\left(t_{i}, \lambda_{i}, x_{i}, u_{i}\right) \\
k_{2} & =f\left(t_{i}+\frac{h}{2}, \lambda_{i}+\frac{h}{2} k_{1}, x_{i}+\frac{h}{2} k_{1}, u_{i}+\frac{h}{2}\right) \\
k_{3} & =f\left(t_{i}+\frac{h}{2}, \lambda_{i}+\frac{h}{2} k_{2}, x_{i}+\frac{h}{2} k_{2}, u_{i}+\frac{h}{2}\right) \\
k_{4} & =f\left(t_{i}+h, \lambda_{i}+h k_{3}, x_{i}+h, u_{i}+h\right) \\
\lambda_{i+1} & =\lambda_{i}+\frac{h}{6}\left(k_{1}+2 k_{2}+2 k_{3}+k_{4}\right), i=0,1,2,3, \cdots, N .
\end{aligned}
$$

\section{Prosedur Solusi Analitik dan Solusi Numerik}

\subsection{Prosedur Analitik}

Berikut prosedur untuk solusi analitik:

(1) Bentuk hamiltonian untuk masalah.

(2) Tulis persamaan diferensial adjoin, kondisi tranversal, dan kondisi optimal dalam $u^{*}, x^{*}$ dan $\lambda$.

(3) Gunakan persamaan optimal $\frac{\partial H}{\partial u}=0$ untuk menyelesaikan $u^{*}$ pada $x^{*}$ dan $\lambda$.

(4) Selesaikan dua persamaan diferensial untuk $x^{*}$ dan $\lambda$ dengan dua kondisi batasan.

(5) Setelah menemukan kondisi optimal dan adjoin, selesaikan kontrol optimal menggunakan formula yang diperoleh dari prosedur ketiga.

\subsection{Prosedur Numerik}

Disini akan diaplikasikan hasil yang didapat pada persamaan (2.9) dan (2.10) untuk memuat aproksimasi numerik pada permasalahan (1.1),(1.2), dan (1.3). Berikut prosedur untuk solusi numerik:

(1) Bentuk Hamiltonian untuk masalah.

(2) Tulis persamaan differensial adjoin, kondisi tranversal, dan kondisi optimal dalam $u^{*}, x^{*}$ dan $\lambda$.

(3) Gunakan persamaan optimal $\frac{\partial H}{\partial u}=0$ untuk menyelesaikan $u^{*}$ pada $x^{*}$ dan $\lambda$.

(4) Selesaikan dua persamaan differensial untuk $x^{*}$ dan $\lambda$ dengan dua kondisi batasan.

(5) Selesaikan $x^{*}$ dan $\lambda$ menggunakan metode Runge-Kutta. 
216 Taufik Hidayat dkk.

\section{Solusi Analitik}

4.1. Masalah Jarak Terpendek Diantara Dua Titik

Dari bentuk permasalahan dibawah ini

$$
\begin{aligned}
\min & \int_{t_{0}}^{T}\left(1+u^{2}\right)^{\frac{1}{2}} d t \\
\text { kendala } & \dot{y}=u, \\
\text { dan } & y\left(t_{0}\right)=y_{0}, y(T) \text { bebas } \\
\text { dimana } & F=\sqrt{1+u^{2}} .
\end{aligned}
$$

Solusi analitik menggunakan prinsip maksimum Pontryagin diperoleh kontrol variabel sebagai berikut

$$
u(t)= \pm \frac{c}{\sqrt{1-c^{2}}}
$$

dan keadaan optimal yang bersesuaian adalah

$$
y(t)= \pm \frac{c}{\sqrt{1-c^{2}}} t+k .
$$

\subsection{Masalah Produksi Coklat}

Dari bentuk permasalahan dibawah ini

$$
\begin{aligned}
\max & \int_{t_{0}}^{2}\left(u^{2}+2 x u-x^{2}\right) d t \\
\text { kendala } & \dot{x}=-u, \\
\text { dan } & x(0)=1, u(0)=0 .
\end{aligned}
$$

Solusi analitik menggunakan prinsip maksimum Pontryagin diperoleh kontrol optimal sebagai berikut

$$
u(t)=\sin (t),
$$

dan keadaan optimal diberikan oleh

$$
x(t)=\cos (t) .
$$

\subsection{Masalah Pendulum}

$$
\begin{aligned}
\min S= & \int_{t_{1}}^{t_{2}}\left(\frac{1}{2} m l^{2} u^{2}-m g l(1-\cos \theta)\right) d t \\
\text { kendala } & \dot{\theta}=u, \\
\text { dan } & \theta\left(t_{1}\right)=\theta_{1}, \theta(T) \text { bebas. }
\end{aligned}
$$

dimana,

$$
F=\frac{1}{2} m l^{2} u^{2}-m g l(1-\cos (\theta)) .
$$


Solusi analitik menggunakan prinsip maksimum Pontryagin diperoleh keadaan optimal

$$
\theta(t)=A \cos w t+B \sin w t
$$

dan kontrol Optimal diberikan oleh

$$
u(t)=w(-A \cos w t+B \sin w t)
$$

\subsection{Perbandingan Solusi Analitik dan Solusi Numerik}

4.4.1. Perbandingan Solusi Analitik dan Numerik Dalam Tabel

Tabel 1. Tabel perbandingan solusi numerik dan solusi eksak masalah geometri jarak terpendek di antara dua titik dengan $h=0,1$

\begin{tabular}{|c|c|c|c|c|c|c|}
\hline$S / N$ & Waktu & $u$ Numerik & $u$ Eksak & $y$ Numerik & $y$ Eksak & $\lambda$ \\
\hline 0 & 0 & 1 & 1 & 2 & 2 & 0.707107 \\
2 & 0.1 & 1 & 1 & 2.105 & 2.1 & 0.707107 \\
3 & 0.2 & 1 & 1 & 2.21 & 2.2 & 0.707107 \\
4 & 0.3 & 1 & 1 & 2.315 & 2.3 & 0.707107 \\
5 & 0.4 & 1 & 1 & 2.42 & 2.4 & 0.707107 \\
6 & 0.5 & 1 & 1 & 2.525 & 2.5 & 0.707107 \\
7 & 0.6 & 1 & 1 & 2.63 & 2.6 & 0.707107 \\
8 & 0.7 & 1 & 1 & 2.735 & 2.7 & 0.707107 \\
9 & 0.8 & 1 & 1 & 2.84 & 2.8 & 0.707107 \\
10 & 0.9 & 1 & 1 & 2.945 & 2.9 & 0.707107 \\
11 & 1 & 1 & 1 & 3.05 & 3 & 0.707107 \\
\hline
\end{tabular}

4.4.2. Perbandingan Solusi Analitik dan Numerik Dalam Gambar

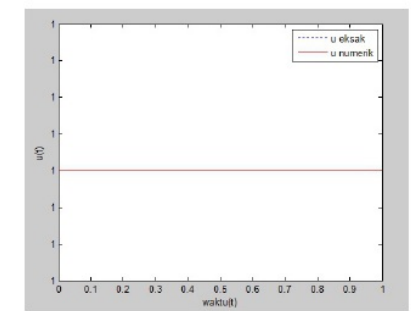

Gambar 1. Grafik perbandin

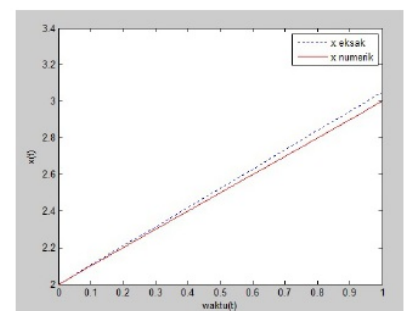

Gambar 2. Grafik perbandingan solusi $x$ numerik dan solusi $x$ eksak masalah geometri jarak 
Tabel 2. Tabel perbandingan solusi numerik dan solusi eksak masalah produksi coklat dengan $h=0,02$

\begin{tabular}{|c|c|c|c|c|c|c|}
\hline$S / N$ & Waktu & $u$ Numerik & $u$ Eksak & $x$ Numerik & $x$ Eksak & $\lambda$ \\
\hline 1 & 0 & 0 & 0 & 1 & 1 & 2 \\
2 & 0.02 & 0.0202 & 0.01999 & 0.9998 & 0.9998 & 2.04 \\
3 & 0.04 & 0.04039 & 0.03998 & 0.999196 & 0.9992 & 2.079184 \\
4 & 0.06 & 0.06058 & 0.05996 & 0.998188 & 0.998201 & 2.117536 \\
5 & 0.08 & 0.08074 & 0.07991 & 0.996776 & 0.996802 & 2.15504 \\
6 & 0.1 & 0.10087 & 0.09983 & 0.994962 & 0.995004 & 2.191682 \\
7 & 0.12 & 0.12097 & 0.11971 & 0.992744 & 0.992809 & 2.227445 \\
8 & 0.14 & 0.14103 & 0.13954 & 0.990124 & 0.990216 & 2.262316 \\
9 & 0.16 & 0.16103 & 0.15931 & 0.987104 & 0.987227 & 2.296279 \\
10 & 0.18 & 0.18097 & 0.17903 & 0.983683 & 0.983844 & 2.329322 \\
11 & 0.2 & 0.20085 & 0.19866 & 0.979864 & 0.980067 & 2.36143 \\
12 & 0.22 & 0.22064 & 0.21822 & 0.975646 & 0.975897 & 2.392590 \\
13 & 0.24 & 0.24036 & 0.23770 & 0.971033 & 0.971337 & 2.422790 \\
14 & 0.26 & 0.25998 & 0.25708 & 0.966026 & 0.966389 & 2.452017 \\
15 & 0.28 & 0.27950 & 0.27635 & 0.960626 & 0.961055 & 2.480259 \\
15 & 0.30 & 0.29891 & 0.29552 & 0.954836 & 0.955336 & 2.507504 \\
17 & 0.32 & 0.31821 & 0.31456 & 0.948658 & 0.949235 & 2.533740 \\
18 & 0.34 & 0.33738 & 0.33348 & 0.942094 & 0.942754 & 2.558958 \\
19 & 0.36 & 0.35642 & 0.35227 & 0.935146 & 0.935896 & 2.583147 \\
20 & 0.38 & 0.37533 & 0.37092 & 0.927817 & 0.928664 & 2.606295 \\
\hline
\end{tabular}
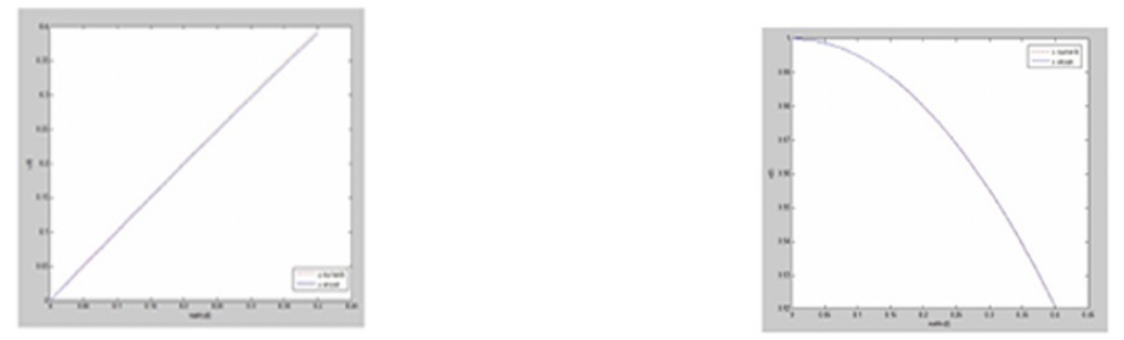

Gambar 3. Grafik perbandingan solusi $u$ numerik dan solusi $u$ eksak masalah produksi coklat Gambar 4. Grafik perbandingan solusi $x$ numerik dan solusi $x$ eksak masalah produksi coklat

\section{Kesimpulan}

Dalam tugas akhir ini telah dilakukan penyelesaian sejumlah masalah kontrol optimal menggunakan prinsip maksimum Pontryagin (analitik) dan juga telah didekati penyelesaiannya menggunakan metode Runge-Kutta (numerik). Penggunaan metode Runge-Kutta lebih baik untuk kasus linier seperti masalah jarak terpendek diantara dua titik daripada kasus non-linier seperti masalah pendulum. Walaupun demikian, galat yang diperoleh sangatlah kecil dan dapat diabaikan untuk kedua kasus linier maupun non-linier. 
Tabel 3. Tabel perbandingan solusi numerik dan solusi eksak masalah pendulum dengan $h=0,01$

\begin{tabular}{|c|c|c|c|c|c|c|}
\hline$S / N$ & Waktu & $u$ Numerik & $u$ Eksak & $x$ Numerik & $x$ Eksak & $\lambda$ \\
\hline 1 & 0 & 2. & 2 & 1 & 1 & -2 \\
2 & 0.01 & 1.991563 & 1.9899 & 1.02005 & 1.019949667 & -1.99156 \\
3 & 0.02 & 1.98302 & 1.979601 & 1.040016 & 1.03979734 & -1.98302 \\
4 & 0.03 & 1.974375 & 1.969105 & 1.059896 & 1.059541034 & -1.97437 \\
5 & 0.04 & 1.965631 & 1.958411 & 1.07969 & 1.079178775 & -1.96563 \\
6 & 0.05 & 1.956794 & 1.947521 & 1.099396 & 1.098708599 & -1.95679 \\
7 & 0.06 & 1.947866 & 1.936437 & 1.119014 & 1.118128553 & -1.94787 \\
8 & 0.07 & 1.938851 & 1.925159 & 1.138542 & 1.137436695 & -1.93885 \\
9 & 0.08 & 1.929753 & 1.913689 & 1.157981 & 1.156631094 & -1.92975 \\
10 & 0.09 & 1.920577 & 1.902027 & 1.177329 & 1.175709831 & -1.92058 \\
11 & 0.1 & 1.911325 & 1.890175 & 1.196584 & 1.194670999 & -1.91132 \\
12 & 0.11 & 1.901960 & 1.878133 & 1.215745 & 1.213512699 & -1.901960 \\
13 & 0.12 & 1.892567 & 1.865905 & 1.234814 & 1.232233050 & -1.892567 \\
14 & 0.13 & 1.883110 & 1.853489 & 1.253790 & 1.250830178 & -1.883110 \\
15 & 0.14 & 1.873592 & 1.840888 & 1.272671 & 1.269302225 & -1.873592 \\
16 & 0.15 & 1.864019 & 1.828104 & 1.291457 & 1.287647342 & -1.864019 \\
17 & 0.16 & 1.854393 & 1.815136 & 1.310147 & 1.305863696 & -1.854393 \\
18 & 0.17 & 1.844718 & 1.801987 & 1.328741 & 1.323949465 & -1.844718 \\
19 & 0.18 & 1.834998 & 1.788657 & 1.347238 & 1.341902839 & -1.834998 \\
20 & 0.19 & 1.825236 & 1.775149 & 1.365638 & 1.359722025 & -1.825236 \\
\hline
\end{tabular}

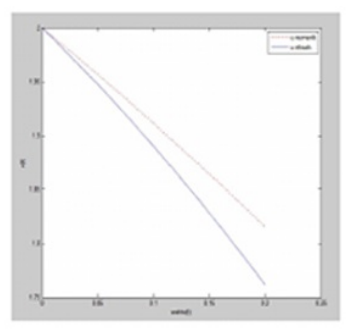

Gambar 5. Grafik perbandingan solusi $u$ numerik dan solusi $u$ eksak masalah pendulum

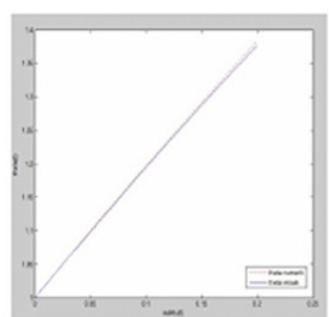

Gambar 6. Grafik perbandingan solusi $\theta$ numerik dan solusi $\theta$ eksak masalah pendulum

\section{Ucapan Terima Kasih}

Penulis mengucapkan terima kasih kepada ibu Haripamyu, ibu Rince Arrival Putri dan bapak Narwen yang telah memberikan masukan dan saran sehingga makalah ini dapat diselesaikan dengan baik.

\section{Daftar Pustaka}

[1] I.R. Khan, dan R. Ohba. 1999. Closed form expressions for the finite difference approximations of first and higher derivatives based on Taylor series. $J$. Comput. Appl. Math. 107: $179-193$.

[2] Oruh, B.I, and Agwu, E.U. 2015. Application of Pontryagyn's Maximum and 
220 Taufik Hidayat dkk.

Runge-Kutta Methods in Optimal Control Problems. IOSR Journal of Mathematics 11(5) : $43-63$.

[3] Desineni, S.N. 2002. Optimal Control System. USA: Idaho State University.

[4] Vicenzo, S.Viorel, A.Sebastian,A. 2012. An Introduction to Optimal Control Problems in Life Sciences and Economics. Italia: Birkhauser.

[5] Garret, R.R. 2015. Numerical Methods for Solving Optimal Control Problems. Knoxville: University of Tennessee.

[6] Andrew,D.L. 2006. The Maximum Principle of Pontryagin in Control and Optimal Control. Canada: Department of Mathematics and Statistics, Queen's University, Kingston.

[7] Spiegel, M.R.1967. Theoretical Mechanics with Introduction to Lagrange's Equation and Hamiltonian Theory. McGraw-Hill, New York.

[8] Borchardt, W.G. and Perrott, A.O. 1959. New Trigonometry for Schools. G.Bell and Sons Limited, London.

[9] Jordan, D.W, Smith, P.2007. Nonlinear Ordinary Differential Equations. Oxford University Press, New York.

[10] Sun, Terje. 2012. Lectures On Optimal Control Theory.Interscience Publishers. 